Immunology Dept., Animal Health Research Institut, Mansoura Branch.

\title{
SEROLOGICAL STUDIES FOR INVOLVEMENT OF AVIAN RESPIRATORY DISEASE IN BROILER CHICKENS IN SHARKIA GOVERNORATE
}

(With 2 Tables)

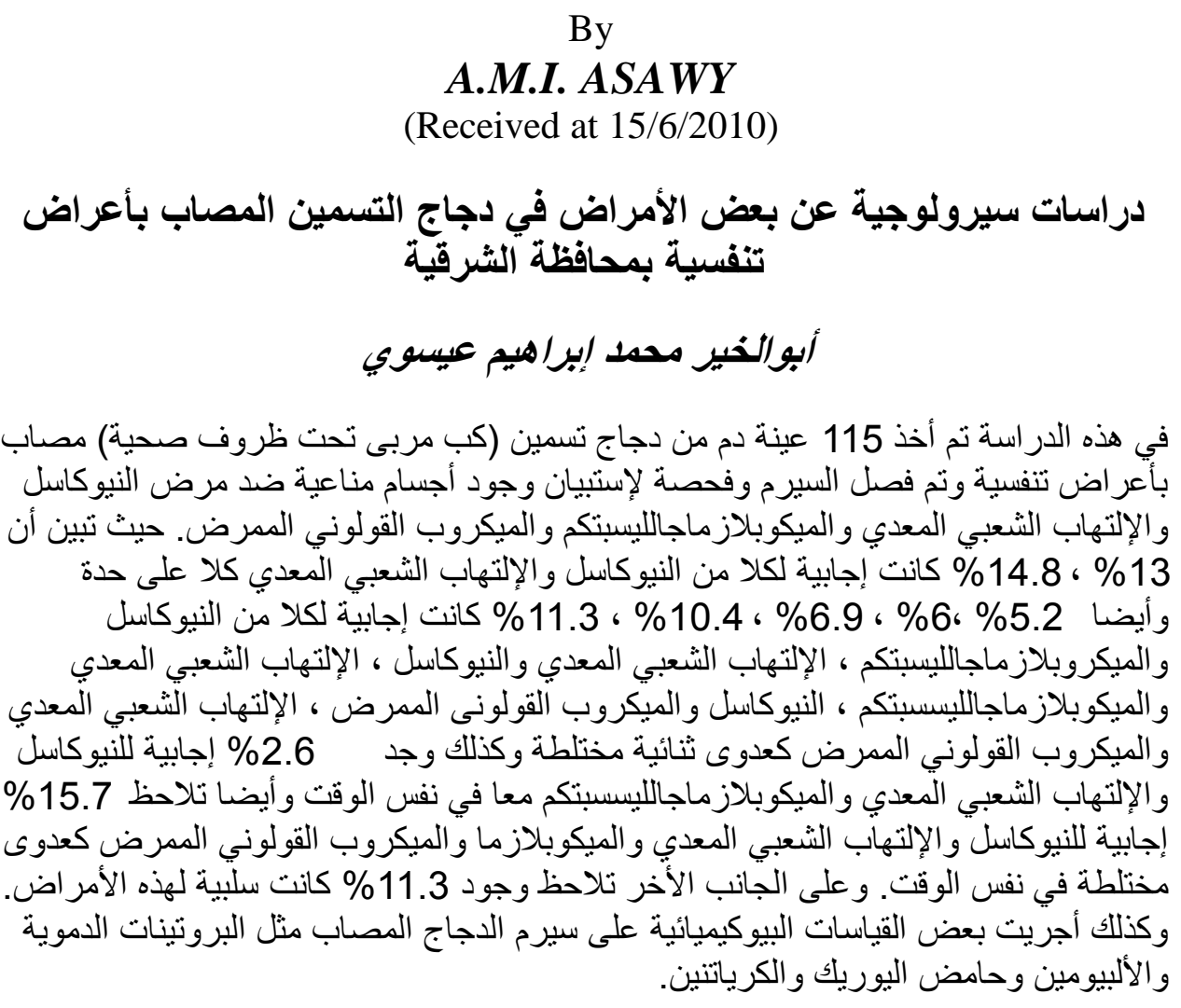

\section{SUMMARY}

Acute respiratory tract infections are of paramount importance in the poultry industry. In Respiratory diseases, involvement of Newcastle disease virus (NDV), Infectious bronchitis virus (IBV), Mycoplasma gallisepticum (MG) and Escherichia coli (E.coli) can be suspected. Most of these usually occur as complex, some being primary while others complicating the situation as secondary pathogens. Broilers have been observed mostly affected with respiratory as complex respiratory disease (CRD), leading to high mortality and huge conomic losses. The results 
showed that $13 \%$ and $14.8 \%$ were infected with NDV and IBV respectively, whereas 5.2, 6.0, 9.6, 10.4 and $11.3 \%$ were infected with both NDV and MG, IBV and NDV, IBV and MG, NDV and E.coli and IBV and E.coli respectively. Furthermore, $2.6 \%$ were infected with IBV, NDV and MG, also $15.7 \%$ were infected with IBV, NDV, MG and E.coli at the same time: On the other hand $11.3 \%$ of the serum samples examined were negative for the above-mentioned respiratory diseases

Key words: Avian respiratory diseases, broiler, New castle, Infectious bronchitis, Mycoplasma

\section{INTRODUCTION}

Respiratory tract infections are of paramount importance in the poultry industry, high mortality may occur in poorly managed cases. The etiology of respiratory diseases is complex, often involving more than one pathogen at the same time (Yashapal et al., 2004).

A wide variety of pathogens have been associated with respiratory infections in poultry, including NDV, IBV, MG and E.coli. These respiratory pathogens are of major importance because they can cause disease independently, in association with each other, or in association with bacterial or viral agents (Yashapal et al., 2004).

Although respiratory diseases are associated with a number of pathogens, infection with E.coli is of particular concern (Rosenberger et al., 1985). E.coli first colonizes the respiratory tract due to the inhalation of contaminated dust (Moulin and Fairbrother, 1999). Factors predisposing to respiratory affections include keeping birds in cold environmental conditions, high dust levels and errors in ventilation leading to high levels of ammonia, these and other stressors can depress the immune system, making the bird more susceptible to mold, bacterial and viral agents (Huchzemeyer, 1994). In poultry flocks Saad (2006) described the serotypes of IBV [Mass, Ark and DE variant - O 72] based on HI - Test. Saad and Dergham (2005) performed a serological and molecular study on MG in commercial flocks suffering from respiratory disease and found that the prevalence of MG in different types of chicken was $73.5 \%$ according to ELISA results and $31.6 \%$ according to the isolation results. In seroprevalence study, Dergham et al. (2006) found antibodies against MG (80.43\%) among broiler breeder flocks. The high prevalence of MG in poultry flocks, confirmed the endemic nature of MG in these flocks. Dergham et al. (2007) reported the appearance of NDV in vaccinated commercial broiler chicken flocks experiencing subclinical 
infectious bursal disease. The incidence and severity of respiratory diseases in broiler chicken flocks have increased because of intensification of broiler industry. IBV, NDV, APV and MG have been isolated several times from commercial broiler chicken flocks (Yashapal et al., 2004). However, the roles of these agents, singly or jointly, in recent outbreaks of respiratory disease in broiler chicken flocks are not clear. Detection of antigen (Ag) or antibody (Ab) against agents has been used widely instead of isolation which is cumbersome and time consuming. This study was designed to clarify the roles of IBV, NDV, MG and E.coli, singly or jointly, in recent outbreaks of respiratory disease in broiler chickens in Sharkia governorate.

\section{MATERIALS and METHODS}

120 One day old chicks, cubb breed, were obtained from Badrashen Company these chicks were reared under hygienic conditions and were fed on starter ration only (Alkahira Company) and kept for 45 days. None of these chicks were vaccinated against NDV, IBV, or MG, but vaccinated against infectious bursal disease (Moderate strain intervet). In the majority of these chicks, signs of respiratory disease usually appeared at 25-35 days of age.

1- 115 blood samples were collected from affected birds, serum was separated and kept at $-20^{\circ} \mathrm{C}$ for serological tests (for detection of antibodies)

2- MG stained antigen (intervet) for plate agglutination test according to Adler (1954).

3- Polyvalent and monovalent E.coli antisera for sero typing of E.coli (Department of Clinical Microbiology, Central Laboratories of Ministry of Health and Population).

4- $1 \%$ chicken RBC (as indicator) to chick NDV by haemagglutination (HA) and haemagglutination inhibition (HI) test according to Cruickshank et al. (1975).

5- ELISA (sigma chemicals and Novus Bio) for detection of antibodies against IBV and MG according to Hassan et al. (1990).

6- Chemicals and Kits for measuring the biochemical parameters in case of respiratory infection according to Monica (2006).

\section{RESULTS}


Table 1: Serological identification of agents in broiler chickens affected with CRD (Dection of antibodies).

\begin{tabular}{|c|c|c|c|c|c|c|c|c|c|}
\hline \multirow{2}{*}{ Pathogens } & \multicolumn{2}{|c|}{ Mixed inf. } & \multicolumn{2}{|c|}{ Single inf. } & \multirow{2}{*}{ Pathogens } & \multicolumn{2}{|c|}{ Mixed inf. } & \multicolumn{2}{|c|}{ Single inf. } \\
\hline & No & $\%$ & No & $\%$ & & No & $\%$ & No & $\%$ \\
\hline NDV & 60 & 25.2 & 15 & 13 & IBV+E.Coli & 13 & 11.3 & & \\
\hline IBV & 61 & 53.04 & 17 & 14.8 & NDV+E.Coli & 12 & 10.4 & & \\
\hline MG & 46 & 40.0 & & & $\mathrm{IBV}+\mathrm{MG}$ & 11 & 9.6 & & \\
\hline E. Coli & 60 & 52.2 & & & $\mathrm{IBV}+\mathrm{NDV}+\mathrm{MG}$ & 3 & 2.6 & & \\
\hline NDV+IBV & 6.0 & 6.0 & & & $\mathrm{IBV}+\mathrm{NDV}+\mathrm{MG}$ & 8 & 15.7 & & \\
\hline $\mathrm{NDV}+\mathrm{MG}$ & 5.2 & 5.2 & & & E.Coli & & & & \\
\hline \multicolumn{10}{|c|}{ No = Number $\quad$ inf. $=$ infection. } \\
\hline \multicolumn{10}{|c|}{ NDV $=$ Newcastle disease virus } \\
\hline \multicolumn{10}{|c|}{ IBV = Infectious bronchitis virus } \\
\hline \multicolumn{10}{|c|}{ MG = Mycoplasma gallisepticum } \\
\hline \multicolumn{10}{|c|}{$\mathrm{CRD}=$ complex respiratory disease } \\
\hline
\end{tabular}

Table 2: Biochemical parameters in broiler chickens affected with CRD.

\begin{tabular}{ll|c|c|}
\hline \multicolumn{2}{|c|}{ Parameter } & Affected serum & Control \\
\hline Total protein * & $(\mathrm{gm} / \mathrm{dl})$ & 4.47 & 3.88 \\
Albumin $*$ & $(\mathrm{gm} / \mathrm{dl})$ & 2.15 & 1.36 \\
Creatinine $* *$ & $(\mathrm{mg} / \mathrm{dl})$ & 2.82 & 0.65 \\
Uric acid ** & $(\mathrm{mg} / \mathrm{dl})$ & 3.06 & 1.32 \\
* Non significant & $(\mathrm{P}<0.05)$ \\
$* *$ Significant &
\end{tabular}

\section{DISCUSSION}

The results of this study showed that $13 \%$ and $14.8 \%$ of these chickens were positive for NDV and IBV antibodies respectively, whereas 5.2, 6.0, 9.6, 10.4 and $11.3 \%$ of these chickens were infected with both NDV and MG, IBV and NDV, IBV and MG, NDV and E.coli, and IBV and E.coli, respectively. Furthermore, $2.6 \%$ of these chickens were infected with IBV, NDV and MG, also $15.7 \%$ were infected with IBV, NDV, MG and E.coli at the same time (Table, 1). On the other hand, $11.3 \%$ of these chickens were negative for the above respiratory diseases.

Respiratory diseases in poultry have been reported to be caused by mixed or single infections with several agents (Watanabe et al., 1977; Sakuma et al., 1981; Yashapal et al., 2004). Because all the tested 
chickens in this study were older than 32 days of age and were suffering from sever respiratory disease, our data suggest exposure of these chickens to any of the 4 pathogens tested. IBV antibodies was detected in $61(53.04 \%)$ of the tested chickens, $17(14.8 \%)$ of these chickens were diagnosed as singly infected with IBV (masschusetts straiv), whereas in the other chickens IBV was combined with other respiratory agents. NDV antibodies was detected in $60(52.2 \%)$ of the tested chickens, $15(13 \%)$ of these chickens were diagnosed as singly infected with NDV, whereas in the other chickens NDV was combined with other respiratory agents. The high rates of IBV and NDV infections in broiler chickens according to the data in this study (Table 1), suggest that IBV and NDV are the important causes of respiratory disease in broiler chickens. It is a common practice to vaccinate broiler chickens against IBV and NDV at least twice as they reach 16 day of age. Despite the use of IBV and NDV vaccines, it is common to find IBV and NDV infections in vaccinated broiler chickens (Dergham et al., 2007), the results of this may partially explain the failure of IBV and NDV vaccines and necessitate revising the vaccination program against IBV and NDV used. However, it is most likely that the chickens used in this study were also naturally exposed to virulent strain of NDV or to new variant strains of IBV. This explain why the vaccines were not covered. MG was detected in $46(40.0 \%)$ of the tested chickens, and all these chickens were suffering from other respiratory agents such as IBV or NDV at the same time. The higher rate of MG infection in broiler chickens in this study was probably due to exposure of the broiler chicken to high virulent strains of MG. The results match those found by Saad and Dergham (2005) and Dergham et al. (2006) and the obtained results disagree with Saif-Edin (1997) and Mowafi (2001) who detect MG antibodies in $36.8 \%$ by slid agglutination test in chicken serum suffering from respiratory disease. E.coli was detected in 60 (52.1\%) and serotyped as $\mathrm{O} 78: \mathrm{K} 80$. This result was not similar to that reported by Kazunori et al. (1990) who isolated and serotyped E.coli O78 (39.1\%) from broiler chickens, and Draual and Woolcock (1994) who isolated E.coli O78 : K 80 from trachea, air sacs, sinuses, subcutaneous and bones of chicken suffering from respiratory disease. 13(11.3\%) tested chickens were diagnosed as negative for the above-mentioned respiratory pathogens. This failure of detection of the above-mentioned respiratory pathogens exclude these pathogens as the cause of this respiratory disease in these chickens. The respiratory diseases in these chickens could have been caused by other respiratory pathogens or by management factors.

Biochemically the creatinine and uric acid were significantly increased in all infected chicken (2.82 and 3.06) respectively and non 
significantly in total protein or albumin (Table 2), these findings nearly agree with El-Boraay and Abo-taleb (2002).

In general, 49(42.6\%) of the tested chickens were positive for any 2 of the above-mentioned respiratory pathogens, 32(27.9\%) were positive for only one of the IBV or NDV, 3(2.6\%) were positive for the IBV, NDV and MG and $18(15.7 \%)$ were positive for the IBV, NDV, MG and E.coli at the same time, but $13(11.3 \%)$ of these chickens did not show positive results for any of the above-mentioned respiratory pathogens. The involvement of IBV, NDV and MG have been found serologically as a cause of CRD in broilers, however there was invariably secondary infection with E.coli.

Our data showed that these respiratory pathogens were the most important causes of respiratory diseases in broiler chickens. Further studies are necessary to assess circulating strains, economic losses caused by infections and coinfections of these pathogens, and the costs and benefits of countermeasures. Furthermore, farmers need to be educated about the signs and the importance of these pathogens.

\section{REFERENCES}

Adler, H.A. (1954): A rapid slide agglutination test for diagnosis of field and laboratory infected chickens and turkey. A.V.M.A: 346-349.

Cruickshank, R.; Duguid, J.P., Marmon, B.P. and Swain, P.H. (1975): Medical Microbiology $12^{\text {th }}$ ed. Vol. 2. Churchill living stone, Edinburgh, London and New York.

Dergham, A.R.; Ehab, A.B. and Rama, H. (2006): Control of Mycoplasma gallisepticum infection in commercial broiler breeder chicken flocks using tilmicosim (provi til ${ }^{\circledR}$ Pomer) oral formulation. Int. J. Poult. Sci. 10: 942-947.

Dergham, A.R.; Rana, H.; Ghassan, K. and Ibrahim, S. (2007): Newcastle in vaccinated commercial broiler chicken flocks experiencing subclinical infections bursal disease in Jordan. J. Poult. Sci. 4: 455-461.

Draual, R. and Woolcock, P.R. (1994): Swollen head syndrome associated with E.Coli and infections bronchitis virus in central valley of California. Avian Pathology, 23: 273-742.

El-Boraay, I.M. and Abo-Taleb, A.M. (2002): Natural and experimental infection with E.Coli and/or Clostridium Perfringens type A in broiler type chickens. Zag. Vet. J. 30 (1) 52-64. 
Hassan, J.O.; Barrow, P.A.; Mockett, A.P. and McLeod, S. (1990): Detection of salmonella typhimurium infection chickens by indirect ELISA. Vet. rec. 126: 519-522.

Huchzermeyer, F.W. (1994): Ostrich Disease. Agriculture Research Council, Pretoria, South Africa. 175-192.

Kazunori Ike; Katsumi Kume; Kazuyoshi Kawahara and Hirofumi Danbara (1990): Serotyping of O and pilus antigens of E.coli strains isolated from chickens with coli-septicemia. Jpn. J. Vet. Sc., 52(5): 1023-1027.

Monica, C. (2000): Cambridge $\mathrm{CB}_{2} 1 \mathrm{RU}$, United Kingdom, $2^{\text {nd }}$ Egyptian ed 2006.

Moulin, M. and Fairbrother, J.M. (1999): Avian Pathogenic E.coli (APEC) Vet. Res. 30, 299-316.

Mowafi, G.M. (2001): Studies on bacterial respiratory affections in chickens. Ph. D. Thesis, Poultry and Rabbit Disease Dep, Fac. of Vet. Med. Cairo University.

Rosenberger, J.K.; Fries, P.A.; Cloud, S.S. and Wilson, R.A. (1985): In vitro and in vivo characterization of Avian E.Coli factors associated with pathogenicity. Avian Dis. 29, 1097-1107.

Saad, M.G. (2006): Infections bronchitis virus serotypes in poultry flock in Jordan. Prev. Vet. Med. 78: 317-324.

Saad, M.G. and Dergham, A.R. (2005): Isolation and molecular characterization of Mycoplasma gallisepticum from commercial chicken flocks with respiratory symptoms in northern Jordan Msc thesis. Jordan univ. Sci Technol., Jrbid.

Saif-Edin, M. (1997): Situation of Mycoplasma infections among chicken in Upper Egypt with evaluation of different diagnostic techniques. Assuit Vet. Med. J., 37(73): 54-66.

Sakuma, S.; Matasuzaki, N. and Yamamoto, O. (1981): Study on respiratory disease in broilers. J. Jpn. Poult. Dis. 4: 246-279.

Stordeur, P. and Mainil, J. (2002): La colibacillose aviaire. Ann. Med. Vet. 146, 11-18.

Watanabe, H.; Nakanishi, K.; Sunaga, T.; Takehara, K.; Mishima, K. Ooe. $R$. and Hattoir, M. (1977): Survey on cause of mortality and condemnations of respiratory diseased broiler flocks. J. Jap. Soc. Poult. Di. 13: 14-46.

Yashapal, S.M.; Devi, P.P. and Sagar, M.G. (2004): Detection of three avian respiratory viruses by single tube multiplex reverse transcription-polymerase chain reaction assay. J. Vet. Diagn. Invest. 16: 244-248. 